\title{
АДАПТИВНА СИСТЕМА КЕРУВАННЯ КОМБІНОВАНИМ ПРОПУЛЬСИВНИМ КОМПЛЕКСОМ 3 НЕЧІТКИМ РЕГУЛЯТОРОМ
}

\begin{abstract}
Стаття присвячена вирішенню проблеми підвищення ефективності прочесів керування судновими комбінованими пропульсивними комплексами за рахунок впровадження диференційного приводгенераторного агрегату та методів адаптивного керування за допомогою нечіткої логіки.

Метою даного дослідження є розробка модель нечіткого виводу, щуо може бути основою для побудови адаптивної системи керування судновим комбінованим пропульсивним комплексом при дії збурюючих факторів навколишнього середовища.

В роботі виконано аналіз структури суднового пропульсивного комплекса. На основі аналізу кінематичної схеми визначено способи стабілізачії частоти обертання валу основного синхронного генератора і частоти напруги змінного трифазного струму на виході диференціального синхронного привід-генераторного агрегату при зміні частоти обертання валу головного двигуна.

Враховуючи нестаціонарний характер навантажень та обмеженість інформації про збурюючі впливи та стан об'єкту, обтрунтовано доцільність застосування нечіткого регулятора для побудови адаптивної системи керування судновим комбінованим пропульсивним комплексом. Розроблено структуру нечіткого регулятора, визначено терми вхідних та вихідних лігнвістичних змінних, обрано функиії належностей, сформовано базу правил, яка враховує зазначені вище обмеження щзоо визначення керуючого впливу - завдання бажаної потужності на гвинті.

Впровадження запропонованих адаптивних системи керування на основі моделі нечіткого виводу дозволяє зменшити вплив збурюючих факторів на роботу гребної установки та стабілізувати параметри напруги бортової мережі

Ключові слова: адаптивна система, нечітка модель, судновий пропульсивний комплекс, диферениіальний привод, валогенератор, оптимальне керування, регулятор.
\end{abstract}

Ю.О.ЛЕБЕДЕНКО Херсонский национальный технический университет ORCID: 0000-0002-1352-9240

А.К. КОЛЕБАНОВ

Херсонская государственная морская академия ORCID: 0000-0002-9618-9105

В.В. ДАНИК

Херсонская государственная морская академия ORCID: 0000-0002-4439-0309

\section{АДАПТИВНАЯ СИСТЕМА УПРАВЛЕНИЯ КОМБИНИРОВАННЫМ ПРОПУЛЬСИВНЫМ КОМПЛЕКСОМ С НЕЧЕТКИМ РЕГУЛЯТОРОМ}

Статья посвящена решению проблемь повышения эффективности процессов управления судовыми комбинированными пропульсивными комплексами за счет внедрения дифференщированного привод-генераторного агрегата и методов адаптивного управления с помощью нечеткой логики.

Целью данного исследования является разработка модели нечеткого вывода, что может быть основой для построения адаптивной системы управления судовым комбинированным пропульсивным комплексом при воздействии возмущающих факторов окружающей среды.

В работе выполнен анализ структуры судового пропульсивного комплекса. На основе анализа кинематической схемы определень способы стабилизации частоты вращения вала основного синхронного генератора и частоты напряжения переменного трехфазного тока на выходе дифференщиального синхронного повод-генераторного агрегата при изменении частоть вращения вала главного двигателя. 
Учитывая нестационарный характер нагрузок и ограниченность информащчи о возмущаюючие воздействия и состояние объекта, обоснована целесообразность применения нечеткого регулятора для построения адаптивной системы управления судовым комбинированным пропульсивным комплексом. Разработана структура нечеткого регулятора, определены термы входных и выходных лигнвистических переменных, выбраны функции принадлежностей, сформирована база правил, которая учитывает указанные выше ограничения по определению управляющего воздействия - задача обеспечения желаемой мощчности на винте.

Внедрение предложенных адаптивных системы управления на основе модели нечеткого вывода позволяет уменьшить влияние возмущающчх факторов на работу гребной установки и стабилизировать параметры напряжения бортовой сети

Ключевые слова: адаптивная система, нечеткая модель, судовой пропульсивный комплекс, дифференциальный привод, валогенератор, оптимальное управление, регулятор.

Yu.O. LEBEDENKO

Kherson National Technical University ORCID: 0000-0002-1352-9240 V.K. KOLEBANOV

ORCID: 0000-0002-9618-9105 Kherson State Maritime Academy

V.V. DANYK

Kherson State Maritime Academy ORCID: 0000-0002-4439-0309

\section{ADAPTIVE CONTROL SYSTEM OF THE COMBINED PROPULSIVE COMPLEX WITH A FUZZY REGULATOR}

The article is devoted to solving the problem of increasing the efficiency of control processes for ship combined propulsion complexes through the introduction of a differentiated drive-generator unit and adaptive control methods using fuzzy logic.

The purpose of this study is to develop a fuzzy inference model, which can be the basis for building an adaptive control system for a ship's combined propulsion complex under the influence of disturbing environmental factors.

The paper analyzes the structure of the ship propulsion system. On the basis of the analysis of the kinematic scheme, methods of stabilizing the rotational speed of the main synchronous generator shaft and the voltage frequency of the alternating three-phase current at the output of the differential synchronous drivegenerator unit when changing the rotational speed of the main engine shaft are determined.

Taking into account the non-stationary nature of the loads and the limited information about the disturbing effects and the state of the object, the expediency of using a fuzzy controller for building an adaptive control system for the ship's combined propulsion complex has been substantiated. The structure of a fuzzy controller has been developed, the terms of input and output linguistic variables have been determined, the functions of accessories have been selected, a rule base has been formed, which takes into account the above restrictions on determining the control action - the task of providing the desired power on the propeller.

The introduction of the proposed adaptive control systems based on the fuzzy inference model allows to reduce the influence of disturbing factors on the operation of the propulsion system and stabilize the voltage parameters of the on-board network

Key words: adaptive system, fuzzy model, ship propulsion complex, differential drive, shaft generator, optimal control, regulator.

\section{Постановка проблеми}

Одним з напрямків підвищення економічності і надійності суднових електроенергетичних систем (СЕЕС) $€$ використання потужності головної енергетичної установки (ГЕУ) для виробництва електроенергії. В даний час на судах широко використовуються СEЕС з прямим і непрямим відбором потужності від ГЕУ. У системах з непрямим відбором потужності привід генераторів забезпечується утилізаційними турбогенераторами або турбінами, які працюють безпосередньо на вихлопних газах ГЕУ. До складу систем з прямим відбором потужності входять валогенераторні установки (ВГУ), в яких привід генераторів здійснюється безпосередньо або через редуктор від ГЕУ [1].

Доцільність застосування систем 3 ВГУ доведена багаторічним досвідом експлуатації. Застосування ВГУ дозволяє відмовитися від експлуатації всіх або частини дизель-генераторів (ДГ) в ходових режимах судна. Зниження експлуатаційних витрат при використанні ВГУ обумовлено більш 
низьким значенням питомого розходу палива головних двигунів порівняно з питомим розходом палива ДГ та скороченням експлуатаційних витрат СЕЕС в цілому [2].

Крім того, у цей час намітилися напрями в розвитку, удосконалюванні й застосуванні суднових енергетичних систем, що містять напівпровідникові перетворювачі частоти, зокрема стосовно дослідження й впровадження комбінованих електромеханічних пропульсивних комплексів та їх систем керування. При цьому особлива увага приділяється питанням підвищення надійності енергопостачання судна, створенню перспективного суднового електроенергетичного обладнання за рахунок інтеграції його в СЕЕС. Крім того, при вирішенні відзначених проблем особлива увага приділяється питанням вибору електричних машин пропульсивних комплексів, валогенераторних установок, а також розробки їх систем керування з урахуванням особливостей роботи й режимів СЕУ та динаміки судна [3].

Найважливішою проблемою в КПК є узгодження між частотою суднової мережі та швидкістю обертання головного двигуна, що може бути забезпечено напівпровідниковими перетворювачами частоти 3 керованими випрямлячами і інверторами з відповідними автоматизованими системами керування, при цьому особливий інтерес представляють валогенераторні установки з диференціальними редукторами.

\section{Аналіз останніх досліджень і публікацій}

Принципіальна електрична схема електромеханічного пропульсивного комплекса 3 синхронноасинхронним диференціальним агрегатом представлений на рис. 1 [4]. Він складається 3 наступних основних елементів і пристроїв: диференціального механізму (ДМ); - безконтактного трифазного основного синхронного генератора (СГ); генератора опори (АД); випрямляча (В) i інвертора (I); регулятора напруги (РН) і регулятора частоти (РЧ), апаратури захисту і управління.

В якості генератора опори може бути використано асинхронна машина (AM), що може працювати як в генераторному режимі, так і в двигуновому. Це дає змогу як відбирати потужність з валопроводу для живлення споживачів у ходовому режимі, так і використовувати синхронний генератор (СГ) як привід гвинта замість головного двигуна. АД в такому режимі забезпечує пуск СГ, розгоняючи його до підсинхронної частоти.

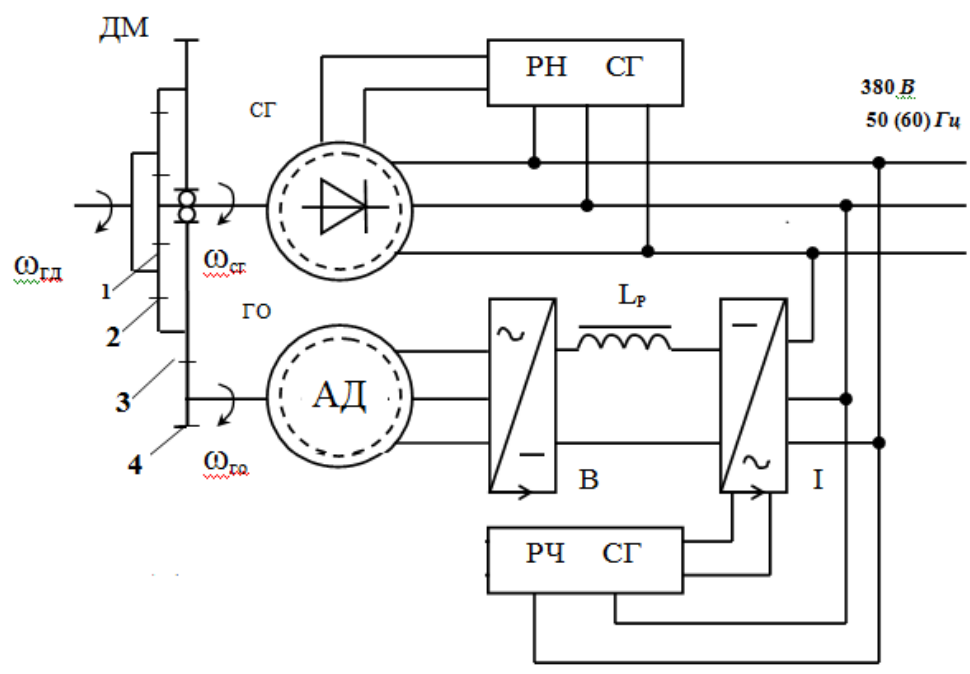

\section{Рис. 1. Принципіальна електрична схема синхронно-асинхронного диференціального агрегату}

Кінематична схема КПК з ДМ наведена на рис. 2.

Окрім зазначених вище компонентів, вона містить також роз'єднувальні муфти М1, М2, М3, що забезпечують необхідну конфігурацію КПК та відповідні обраному режиму функціонування (РTI/РTO/РТН) напрямки передачі механічної енергії [5].

Таким чином, стабілізації частоти обертання валу основного синхронного генератора, а отже, i частоти напруги змінного трифазного струму на виході диференціального синхронного привідгенераторного агрегату при зміні частоти обертання валу ГД забезпечується відповідною зміною частоти обертання генератора опори за допомогою регулювання його механічного моменту зміною величини активної потужності, що передається від генератора опори через випрямляч і інвертор в мережу змінного струму. При цьому в сталому режимі роботи активні потужності генераторів повинні бути перерозподілені між собою таким чином, щоб на всьому діапазоні частот обертання ГД при різних величинах навантаження на виході диференціального синхронного привід-генераторного агрегату наведені механічні моменти основного синхронного генератора і генератора опори були рівні між собою. 


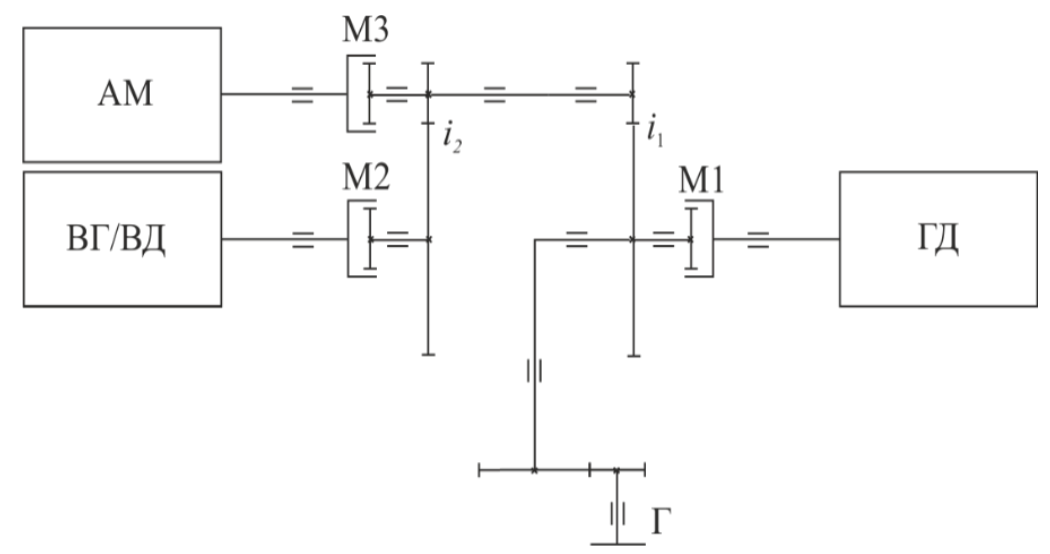

Рис. 2. Кінематична схема синхронно-асинхронного диференціального агрегату

Це може бути досягнуто наступними шляхами [6]:

- зміною величини напруги постійного струму на вході інвертора при постійному значенні кута випередження;

- зміною кута випередження інвертора при постійному значенні напруги на його вході;

- зміною напруги на виході генератора опори при використанні некерованого випрямляча;

- зміною напруги на виході керованого випрямляча допомогою зміни кута управління;

- при змішаному управлінні.

Враховуючи випадковий характер навантажень як з боку електричної енергосистеми, так і безпосередньо рухової установки, що ускладнює процедуру пошуку оптимального керування в реальному часі, доцільно підвищити ефективність керування КПК за рахунок впровадження нечітких алгоритмів.

Формулювання мети дослідження

Метою даного дослідження є розробка модель нечіткого виводу, що може бути основою для побудови адаптивної системи керування судновим комбінованим пропульсивним комплексом при дії збурюючих факторів навколишнього середовища.

Викладення основного матеріалу дослідження

Виходячи 3 рис. 1, блок оптимізації системи керування КПК має визначати параметри налаштувань регулятора обертів ВГ, що здійснює керування ПЧ генератора опори. Проведені дослідження на комп'ютерній моделі показали, що достатню ефективність та прийнятні показники якості перехідних процесів забезпечує ПІ-алгоритм керування, при чому в залежності від ступеня навантаження ГД для забезпечення необхідної тривалості перехідних процесів необхідно модифікувати саме пропорційну складову регулятора завдання швидкості обертання ГО [7].

Таким чином, можна запропонувати наступну структуру нечіткого регулятора КПК з блоком оптимізації, наведену на рис. 3.

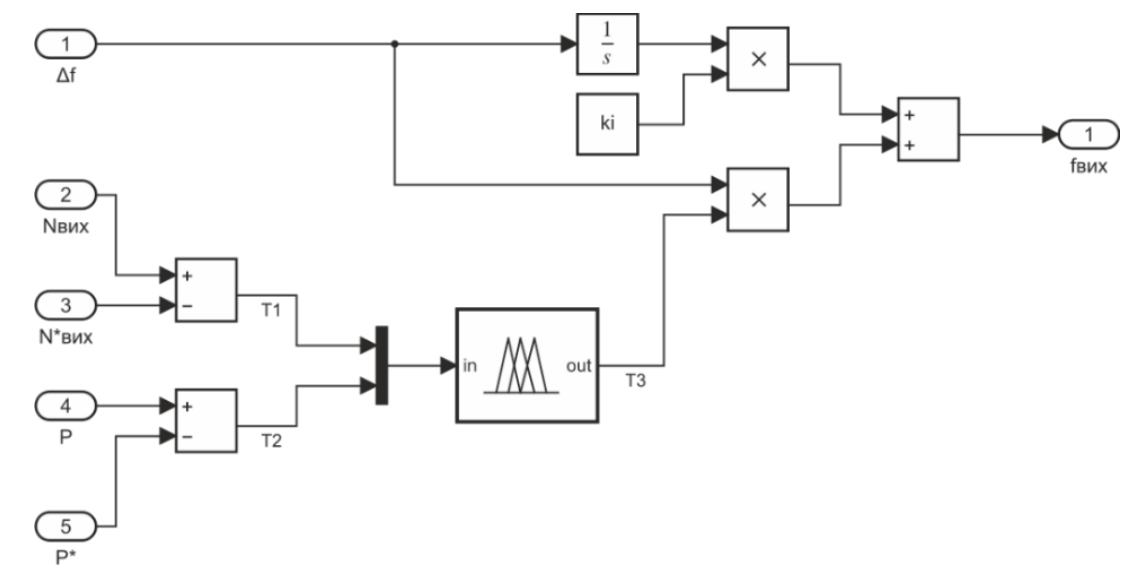

Рис. 3. Структура нечіткого регулятора КПК з ДМ

Основою регулятора $є$ ПІ-регулятор, пропорційний коефіцієнт якого визначається за допомогою моделі нечіткого виводу, в залежності від потужностей КПК та СЕЕС згідно функціонала мети: 


$$
J=\int_{0}^{t}\left[N_{\text {виX }}{ }^{*}(t)-N_{\text {BиX }}(t)\right]^{2} \cdot d t,
$$

де $N_{B И X}{ }^{*}(t)$ та $N_{B и X}(t)$ - задана та діюча механічні потужності на гвинті судна; та обмежень:

$$
P_{\text {Eл }}+P_{\text {КПК }}=P_{B . C \Pi} \cdot
$$

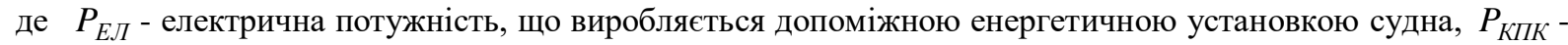
електрична потужність, що відбирається від КПК, $P_{B . C П}$ - необхідна потужність споживачів.

Згідно запропонованого функціонала мети (1) та обмежень (2), контролер нечіткої логіки аналізує дві вхідні змінні: нормоване середньоквадратичне відхилення вихідної потужності $\Delta N$ та нормоване відхилення між вироблюваною та споживаною потужністю СЕЕС $\Delta P$. Тоді як вихід нечіткого контролера - бажаний рівень нормованої частоти генератора опори $f_{\text {вих. }}^{*}$

Відповідні терми нечітких змінних адаптивного регулятора КПК з ДМ наведено в таблиці 1.

\begin{tabular}{|c|c|c|c|}
\hline Tepм & Назва & Межі & Опис \\
\hline$T 1$ & $\begin{array}{l}\text { Нормоване } \\
\text { середньоквадратичне } \\
\text { відхилення } \quad \text { вихідної } \\
\text { потужності }\end{array}$ & $\begin{array}{l}\Delta N \quad=\{\text { «енша», } \\
\text { «середня», } \\
\text { «більша» }\}, \\
\Delta N \in[-1 ; 1] .\end{array}$ & $\begin{array}{l}\text { Вхідна нечітка змінна. Різниця між заданою } \\
\text { потужністю на гвинті та дійсним значенням. } \\
\text { Обмеження означає максимально можливу } \\
\text { різницю між потужністю, що забезпечується } \\
\text { КПК, та потужністю завдання. }\end{array}$ \\
\hline$T 2$ & $\begin{array}{l}\text { Нормоване відхилення } \\
\text { між вироблюваним та } \\
\text { споживаним струмом, }\end{array}$ & $\begin{array}{l}\Delta P=\{\text { «низький», } \\
\text { «середній», } \\
\text { «високий» }\} \\
\Delta P \in[0 ; 6] .\end{array}$ & $\begin{array}{l}\text { Вхідна нечітка змінна. Обмеження означає } \\
\text { максимально допустиме значення збурюючої } \\
\text { величини - споживаного струму, } \\
\text { нормованого до номінального. }\end{array}$ \\
\hline$T 3$ & $\begin{array}{lr}\text { Бажаний } & \text { рівень } \\
\text { нормованої } & \text { частоти } \\
\text { генератора опори }\end{array}$ & $\begin{array}{l}f_{\text {вих }}^{*}=\{\text { «низька», } \\
\text { «середня», } \\
\text { «висока»\}, } \\
f_{\text {вих }}^{*} \in[0 ; 2] .\end{array}$ & $\begin{array}{l}\text { Вихідна нечітка змінна. Обмеження означає, } \\
\text { що в залежності від значення вхідних терм- } \\
\text { множин, відбувається коригування бажаного } \\
\text { рівня напруги. }\end{array}$ \\
\hline
\end{tabular}

Терм-множини нечітких змінних регулятора КПК

Нечіткий набір для кожного входу розробляється шляхом визначення відповідних функцій належності. Функції належності вхідних змінних та вихідної наведено на рис. 4.

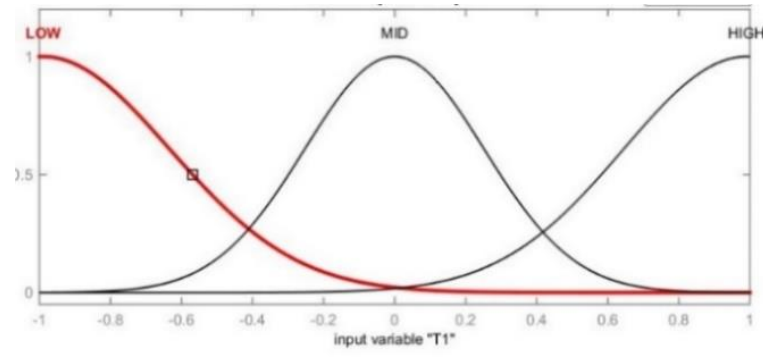

a)

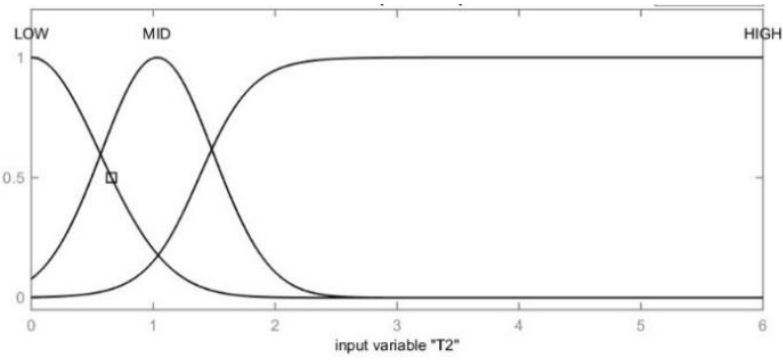

б)

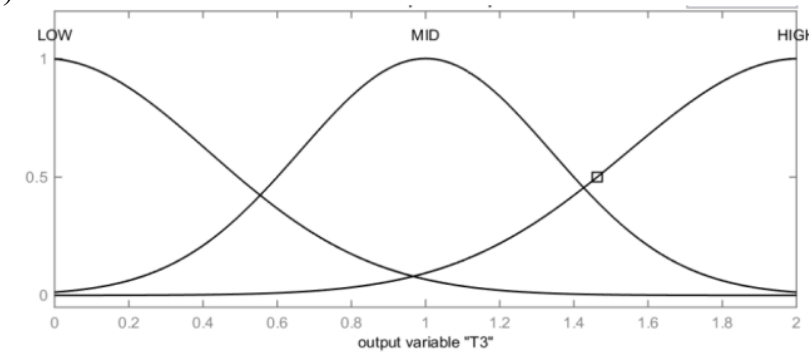

в)

Рис. 4. Функції належності вхідних (a, б), вихідної (в) змінних 
Нечіткий набір застосовується для подання нечітких входів і виходів керування, щоб кількісно визначити значення лінгвістичної змінні, лінгвістичні значення та лінгвістичні правила [8]. Крім того, нечіткі набори використовуються для евристичної кількісної оцінки інформації при роботі КПК за допомогою бази правил.

Як для покриття діапазону потужності ГД, так і з точки зору запасу потужності СЕЕС, достатньо трьох функцій належності. Іншими словами, початкові чотири вхідні змінні замінюються на LOW, MID, HIGH (див. рис. 3,a, б).

База правил у цьому дослідженні будується, виходячи з необхідності порівняння миттєвих значень двох входів, тобто потреби в електричній потужності, різниця між поточною потужністю ГД та необхідною.

База правил нечіткого регулятора зазвичай містить нечіткі висловлення у формі "ЯКЩО-ТО" База правил запропонованого регулятора КПК наведена в табл. 2.

База правил нечіткого регулятора КПК

\begin{tabular}{|c|c|c|c|}
\hline № & T1 & T2 & T3 \\
\hline 1. & LOW & LOW & HIGH \\
\hline 2. & LOW & MID & HIGH \\
\hline 3. & LOW & MID & HIGH \\
\hline 4. & MID & LOW & MID \\
\hline 5. & MID & HIGH & MID \\
\hline 6. & MID & LOW & HIGH \\
\hline 7. & HIGH & MID & LOW \\
\hline 8. & HIGH & HIGH & MID \\
\hline 9. & HIGH & & \\
\hline
\end{tabular}

База правил сформована таким чином, щоб, з одного боку, забезпечувати форсування керуючого впливу при низькій потужності споживання та відхиленні механічної потужності. 3 іншого, велика розбіжність між необхідною та поточною потужностями може викликати перевантаження механізму, тому в правилах, що відповідають такій ситуації, значення вихідної нечіткої змінної буде меншим за максимально можливе.

Для моделювання нечіткого регулятора використаємо бібліотеку fuzzy програмного пакету Matlab Simulink. Нечіткі множини в модулях фазифікації задаються функціями приналежностей сигмоїдного типу(див. рис. 3) по чотирьох точках за допомогою графічного інтерфейсу.

Правила нечіткого виводу для розроблюваної системи представляються за допомогою редактора правил. Зв'язок кількох вхідних змінних у нечітких правилах виконується за допомогою логічних конструкцій «ЯКЩО-ТО». Кожному введеному правилу привласнюється ваговий коефіцієнт, рівний 1.

Поверхні рішення для вихідної змінної Т3, що формуються за розробленою базою правил, наведено на рис. 5, приклад розрахунку - на рис. 6.

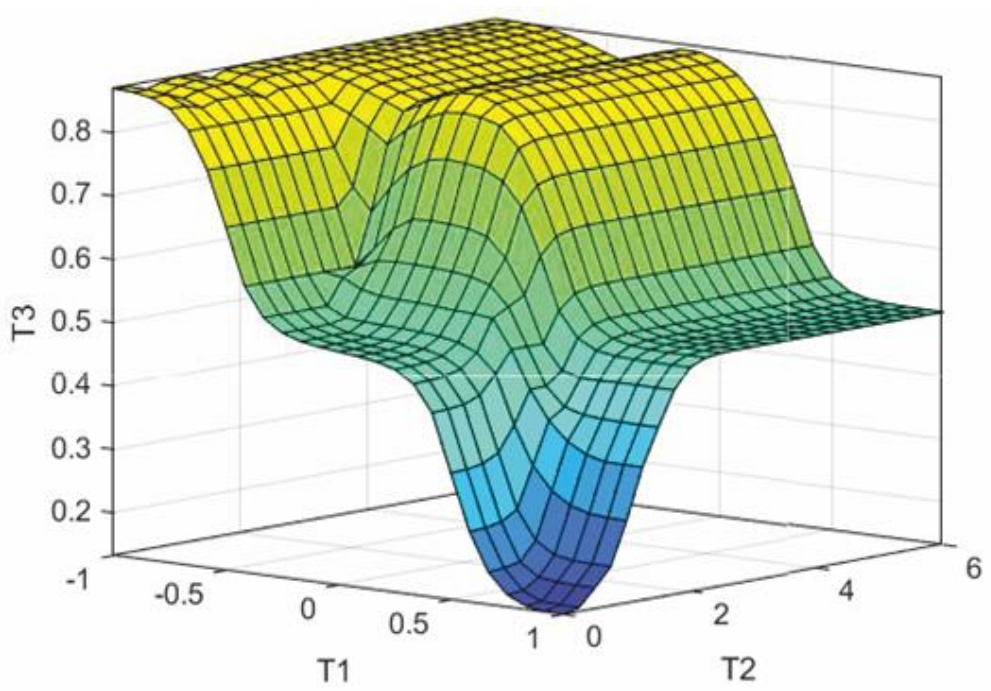

Рис. 5. Поверхня рішень нечіткої змінної Т3 

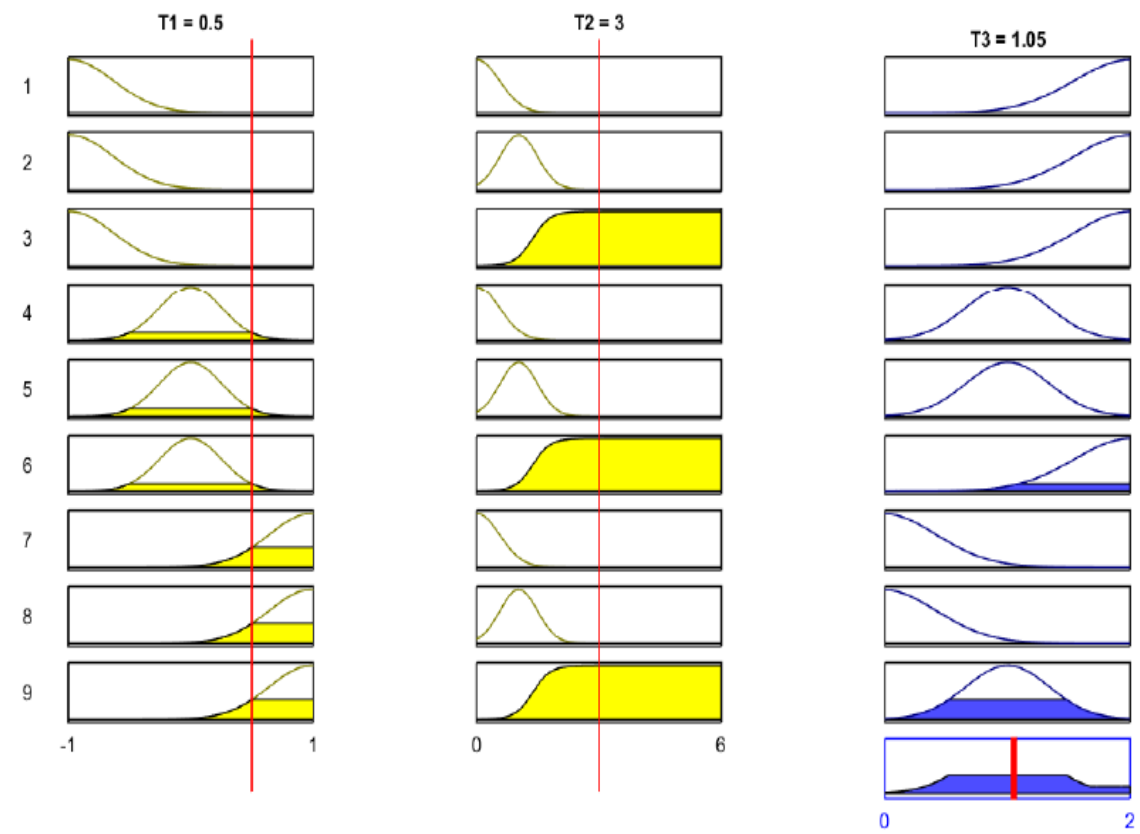

Рис. 6. Приклад розрахунку нечіткої змінної Т3

Фазифікація і дефазифікація здійснюється програмно за алгоритмом Мамдані. Знаходження чіткого значення параметра регулятора частоти обертання ГО 3 отриманої нечіткої змінної Т3 здійснюється за методом центра ваги [8].

Логічний вивід здійснюється шляхом агрегування за допомогою згортки масиву та обчислення значення ступеня істинності правила. Далі виконується акумуляція всіх правил шляхом формування результуючої функції для кожної змінної окремо. У результаті акумуляції отримується загальна функція приналежності для вихідної змінної Т3 за всіма термами.

\section{Висновки}

1. При роботі в експлуатаційних режимах КПК необхідно враховувати вимоги до забезпечення балансу потужностей, зокрема механічною на гвинті судна та електричної потужності в судновій електромережі.

2. Через випадковий характер навантажень як з боку електричної енергосистеми, так і безпосередньо рухової установки, реалізація алгоритмів оптимального управління в реальному часі $\epsilon$ ускладненою.

3. Підвищення ефективності керування та компенсація дії зовнішніх збурень можливе завдяки впровадженню адаптивних систем керування КПК на основі нечітких алгоритмів.

4. Розроблено структуру нечіткого регулятора, що визначає оптимальні параметри налаштувань контуру регулювання генератора опори КПК, визначено терми-множини вхідних нечітких змінних, їх функції належності, сформульовано база правил, яка враховує обмеження щодо визначення керуючого впливу - завдання бажаної потужності на гвинті.

5. Результати комп'ютерного моделювання роботи комбінованого пропульсивного комплекса із застосуванням розробленого адаптивного регулятора 3 нечіткою моделлю нечітким підтверджують ефективність запропонованих рішень.

6. Впровадження запропонованих адаптивних системи керування на основі моделі нечіткого виводу дозволяє зменшити вплив збурюючих факторів на роботу гребної установки та стабілізувати параметри напруги бортової мережі

\section{Список використаної літератури}

1. Седаков, Л.П., Баракан Г.Х., Калинина Л.И. Резервы повышения экономичности современных судовых дизельных энергетических установок. Судостроение. 1987. № 11. С. 20-25.

2. Шпринцин В.Н. Судовые валогенераторы. Л.: Судостроение, 1965. 237 с.

3. Луковцев В.С., Щербинин В.А. Особенности работы комбинированного двигателя в составе судовой пропульсивной установки. Научно-технический сборник «Судовые энергетические установки». Вып.№21. С. 87-90.

4. Ищенко И.М., Данык В.В. Дифференциальный синхронноасинхронный привод гребных винтов судов с электродвижением. Фундаментальные и прикладные исследования, разработка и применение 
высоких технологий в промышленности и экономике: материалы XX междунар. научно-практ. конф., г. Санкт-Петербург, Россия, 24-26 ноября 2015 г. C.64-65.

5. Geertsma R.D., Negenborn R.R., Visser K., Hopman J.J. Design and control of hybrid power and propulsion systems for smart ships: A review of developments. Appl. Energy. 2017. 194. 30-54 pp.

6. Ищенко И.М., Данык В.В. Дифференциальный синхронноасинхронный привод гребных винтов судов с электродвижением. Фундаментальные и прикладные исследования, разработка и применение высоких технологий в промышленности и экономике: материалы XX междунар. научно-практ. конф., г. Санкт-Петербург, Россия, 24-26 ноября 2015 г. С.64-65.

7. Іщенко I.M., Даник В.В., Лебеденко Ю.О. Оптимізація процесів керування судновими комбінованими пропульсивними комплексами. FS-2019: матеріали міжнар. наук.-практ. конф., присвяченої пам'яті професорів Фоміна Ю.Я. і Семенова В.С., м. Одеса - м. Стамбул - м. Одеса, 24-28 квіт. 2019. Одеса. 2019. С.: 225-227.

8. Гостев В.И. Нечеткие регуляторы в системах автоматического управления. К.: Радіоаматор. 2008.972 c.

\section{References}

1. Sedakov, L.P., Barakan G.Kh., Kalinina L.I. Rezervy povysheniya ekonomichnosti sovremennykh sudovykh dizel'nykh energeticheskikh ustanovok. Sudostroyeniye. 1987. № 11. 20-25 pp.

2. Shprintsin V.N. Sudovyye valogeneratory. L.: Sudostroyeniye, 1965. 237 p.

3. Lukovtsev V.S., Shcherbinin V.A. Osobennosti raboty kombinirovannogo dvigatelya v sostave sudovoy propul'sivnoy ustanovki. Nauchno-tekhnicheskiy sbornik «Sudovyye energeticheskiye ustanovki». Vyp.№21. 87$90 \mathrm{pp}$.

4. Ishchenko I.M., Danyk V.V. Differentsial'nyy sinkhronnoasinkhronnyy privod grebnykh vintov sudov s elektrodvizheniyem. Fundamental'nyye i prikladnyye issledovaniya, razrabotka i primeneniye vysokikh tekhnologiy v promyshlennosti i ekonomike: materialy XX mezhdunar. nauchno-prakt. konf., g. Sankt-Peterburg, Rossiya, 24-26 noyabrya 2015 g. 64-65 pp.

5. Geertsma R.D., Negenborn R.R., Visser K., Hopman J.J. Design and control of hybrid power and propulsion systems for smart ships: A review of developments. Appl. Energy. 2017. 194. 30-54 pp.

6. Ishchenko I.M., Danyk V.V. Differentsial'nyy sinkhronnoasinkhronnyy privod grebnykh vintov sudov s elektrodvizheniyem. Fundamental'nyye i prikladnyye issledovaniya, razrabotka i primeneniye vysokikh tekhnologiy v promyshlennosti i ekonomike: materialy XX mezhdunar. nauchno-prakt. konf., g. Sankt-Peterburg, Rossiya, 24-26 noyabrya 2015 g. 64-65 pp.

7. Íshchenko Í.M., Danik V.V., Lebedenko YU.O. Optimízatsíya protsesív keruvannya sudnovimi kombínovanimi propul'sivnimi kompleksami. FS-2019: materíali mízhnar. nauk.-prakt. konf., prisvyachenoï pam'yatí profesorív Fomína YU.YA. í Semenova V.S., m. Odesa - m. Stambul - m. Odesa, 24-28 kvít. 2019. Odesa. 2019. 225-227 pp.

8. Gostev V.I. Nechetkiye regulyatory v sistemakh avtomaticheskogo upravleniya. Kyiv: Radíoamator. 2008.972 p. 